\title{
Strategies to facilitate the development of uncloned or cloned infectious full-length viral cDNAs: Apple chlorotic leaf spot virus as a case study
}

Fater Youssef ${ }^{1,2}$, Armelle Marais ${ }^{1,2}$, Chantal Faure ${ }^{1,2}$, Pascal Gentit ${ }^{3}$ and Thierry Candresse ${ }^{1,2^{*}}$

\begin{abstract}
Background: Approaches to simplify and streamline the construction of full-length infectious CDNA clones (FLcDNAs) are needed. Among desirable improvements are the ability to use total nucleic acids (TNA) extracts from infected hosts (to bypass viral purification limitations) for the direct one-step amplification of large FL-cDNAs, the possibility to inoculate plants with uncloned FL-cDNAs and the simplified cloning of these large molecules.

Results: Using the $7.55 \mathrm{~kb}$ genome of Apple chlorotic leaf spot trichovirus (ACLSV) approaches allowing the rapid generation from TNA extracts of FL-cDNAs under the control of the T7 promoter and the successful inoculation of plants using in vitro transcripts obtained from these uncloned amplification products have been developed. We also show that the yeast homologous recombination system permits efficient cloning of FL-cDNAs and the simultaneous one-step tailoring of a ternary Yeast-Escherichia coli-Agrobacterium tumefaciens shuttle vector allowing efficient inoculation of both herbaceous and woody host plants by agroinfiltration.

Conclusions: The fast and efficient strategies described here should have broad applications, in particular for the study of "difficult" plant viruses, such as those infecting woody hosts, and potentially for other, non plant-infecting viral agents.
\end{abstract}

\section{Background}

Over the past 25 years, our ability to discover and characterize viral agents has steadily improved, leading to a constant flow of discovery of novel plant viruses as testified by the literature and by the constant increase in the number of viral species described in successive reports of the International Committee for the Taxonomy of Viruses [1]. The development of next generation sequencing (NGS) techniques promises to increase the rate at which novel plant viruses will be discovered in coming years $[2,3]$. At the same time, our ability to unambiguously establish the contribution of newly characterized viral agents to particular plant diseases has not improved. The fulfilling of Koch's postulates has been modified by L. Bos to be adapted to viruses, and

\footnotetext{
* Correspondence: tc@bordeaux.inra.fr

'Equipe de Virologie, INRA, UMR 1332 Biologie du Fruit et Pathologie, BP81,

33883 Villenave d'Ornon cedex, France

Full list of author information is available at the end of the article
}

represents a fundamental point in plant virology [4]. With the application of these postulates, the role of many viruses in diseases has been deciphered. But for many other plant viruses, technical problems in the identification of alternative herbaceous hosts, in purification or in experimental transmission have prevented the analysis of their contribution to particular diseases [4]. This is especially true for viruses affecting vegetatively propagated crops [5-7], which often have the added disadvantage of being frequently mixed infections [8]. Thus, for many viruses, the demonstration of their involvement in a given disease has not been completed, but has only been postulated on the basis of an association with symptomatic plants [see for example $[9,10]]$.

One strategy to bypass the problems encountered with fulfilling of Koch's postulates involves the use of fulllength cDNAs clones (FL-cDNAs) (or DNA clones in the case of DNA viruses) from which infectious RNA transcripts can be obtained in vitro or in vivo [11]. 
However, the construction of infectious FL-cDNAs is still often complicated and time-consuming for many reasons: the difficulty to optimize a standardized protocol for all viruses, the necessity of a perfect junction of the promoter and 5' end of the viral sequence, the difficulty to clone large cDNA molecules and the frequent instability of such clones [11].

These difficulties have largely limited the use of FLcDNAs to studies on reverse genetics of well characterized viruses, which have provided access to valuable information on the expression of viral genomes, their replication and mechanisms involved in the infection cycle. They also provided further insight on the functions of different viral proteins or the mechanisms of interaction between viruses and their host plant(s) or vector(s).

However, despite their potential to address such questions, the use of infectious FL-cDNAs to confirm or refute etiological hypotheses has been rather limited [12-15]. In a recent example, the construction of an agroinfiltrable FL-cDNA clone of Citrus leaf blotch virus (CLBV) allowed the demonstration that CLBV is the causal agent of the Dweet mottle disease and that in single infections it does not cause the bud union crease disease [16]. An example of the widespread use of infectious constructs for etiology studies is in the Geminiviridae family, for which efficient techniques exist for the development of both cloned or uncloned infectious DNA constructs $[17,18]$. However, there are additional technical difficulties when working with RNA viruses that are responsible for the limited use of FL-cDNAs in etiology studies of RNA plant viruses.

Simplified strategies for the easier and faster development of infectious FL-cDNA for etiology studies of plant viruses should have a number of desirable properties. First, is the ability to use total nucleic acids (TNA) extracts from infected plants as template for cDNA synthesis [12,19], rather than purified viral RNA as this would bypass the need to propagate and purify the virus. Second, is the ability to use long distance PCR [20] to amplify the viral genomes as single, large PCR fragments, a technique that has been used rarely for genomes longer than $7 \mathrm{~kb}[12,19,21-23]$. In a number of situations, cloning of the infectious FL-cDNA may not be necessary to validate an etiology hypothesis, so that the ability to infect plants using uncloned PCR products is also of potential interest [24-26]. Lastly, when cloning of FL-cDNAs is used, techniques that facilitate the cloning of long PCR fragments or the one-step assembly of complex constructions would be of great interest. One little used strategy with such a potential is the use of the efficient homologous recombination machinery of the yeast Saccharomyces cerevisiae. Until recently, the application of this system has been limited to yeast genetics and to the construction of plasmids and yeast artificial chromosomes (YACs) [27]. The full power of this approach has been demonstrated recently by the assembly of 25 overlapping DNA fragments to generate a synthetic mycoplasma genome in a single step [28]. In virology, the application of this strategy has been used as an alternative to difficult classical cloning in Escherichia coli, as in the case of Dengue virus type 2, where three cDNA fragments of the virus were assembled by homologous recombination in yeast to generate an infectious FL-cDNA [29]. The fact that recombination is very efficient, even with short, 20-30 nucleotides-long overlap regions between fragments created using PCR primers has facilitated the construction of recombinant viral genomes $[30,31]$.

In the present study, Apple chlorotic leaf spot virus (ACLSV), the type species of the genus Trichovirus within the family Betaflexiviridae [1,32,33], was used as a model system for the development of approaches that fulfill some of the above criteria for improved preparation of infectious FL-cDNAs. The genomic RNA of ACLSV is about $7.55 \mathrm{~kb}$ in length $[34,35]$ and an infectious FL-cDNA for a Japanese isolate from apple (P205) under the control of the CaMV 35 S promoter has been constructed [36]. We report on the long distance PCR amplification from TNA extracts of infectious FLcDNAs under the control of the T7 promoter. We also show that the yeast homologous recombination system permitted the efficient cloning of such large FL-cDNAs and the simultaneous one-step tailoring of a ternary yeast-E. coli-Agrobacterium tumefaciens shuttle vectors allowing efficient infection of plants by agroinfiltration.

\section{Results}

Long distance RT-PCR amplification of ACLSV FL-CDNAs under the control of the T7 promoter and infectivity in various hosts of the transcripts synthesized in vitro from the uncloned PCR products

The feasibility of amplification of ACLSV FL-cDNAs under the control of the $\mathrm{T} 7$ promoter from crude nucleic acids extracts obtained from infected plants was evaluated. The amplification was performed using primers FLAC3 and FLAC5 (Table 1), the later integrating a $18 \mathrm{bp}$ sequence corresponding to the $\mathrm{T} 7$ promoter, including the $\mathrm{G}$ corresponding to the transcription start site, fused to the $25 \mathrm{nt} 5^{\prime}$ terminal ACLSV genomic sequence. As a consequence, transcripts synthesized on a PCR product integrating this primer are expected to have a single 5' extra $G$ as compared to the wild type viral sequence. A good yield of a PCR product of the expected $\sim 7.6 \mathrm{kbp}$ size was obtained will all three polymerases evaluated (Figure 1a and results not shown) but amplification results using the Phusion ${ }^{\circledR}$ High Fidelity DNA Polymerase (Finnzyme) proved somewhat erratic 
Table 1 Primers used for the amplification of either ACLSV FL-CDNA or the different PCR fragments used for ACLSV FL-cDNA cloning by homologous recombination in Saccharomyces cerevisiae

\begin{tabular}{|c|c|c|c|}
\hline $\begin{array}{l}\text { Primer } \\
\text { name }\end{array}$ & Sequence $5^{\prime}-3^{\prime a}$ & Amplified fragment & $\begin{array}{c}\text { Size } \\
(\mathbf{k b p})\end{array}$ \\
\hline $\begin{array}{l}\text { FLAC5 } \\
\text { FLAC3 }\end{array}$ & $\frac{\text { TAATACGACTCACTATAGTGATACTGATACAGTGTACACTCACG }}{\underline{\underline{T_{(30)}}} \text { GTAGTAAAATATTTAAAAGTCTACAG }}$ & T7-FL-CDNA ${ }^{b}$ & 7.5 \\
\hline $\begin{array}{l}\text { 30ANotvec } \\
\text { T7ACR }\end{array}$ & $\begin{array}{c}\mathbf{A}_{(30)} \text { GCGGCCGCTCTAGCTAGAAGCTTITGTTCCCTTIAGTG } \\
\text { GTATCAGTATCACTATAGTGAGTCGTATTAAGATCGGACCCTGGCGTAATAGC }\end{array}$ & Yeast-pBS70T ${ }^{b}$ & 5.2 \\
\hline $\begin{array}{l}\text { ACLSVF } \\
\text { FLAC3 }\end{array}$ & 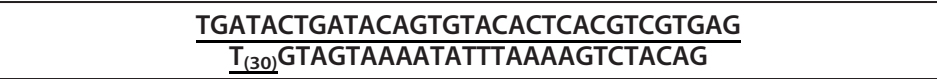 & $\mathrm{FL}^{-C D N A^{c}}$ & 7.5 \\
\hline $\begin{array}{l}\text { 30ACNOSF } \\
\text { AC35SR }\end{array}$ & $\begin{array}{c}\text { TAAATATTTACTACA(30)CGGGTACCGAGC } \\
\text { CGACGTGAGTGTACACTGTATCAGTATCACCTCTCCAAATGAAATGAACTTCCTTATA }\end{array}$ & Yeast-pBS70T & 5.2 \\
\hline $\begin{array}{l}\text { ACPCR1F } \\
\text { FLAC3 }\end{array}$ & $\frac{\text { AGAGGTGATACTGATACAGTGTACACTCACG }}{\underline{\text { T(30) }^{(} \text {GTAGTAAAATATTTAAAAGTCTACAG }}}$ & FL-CDNA (PCR1) & 7.5 \\
\hline $\begin{array}{l}\text { ACPCR2F } \\
\text { PCR2 }\end{array}$ & 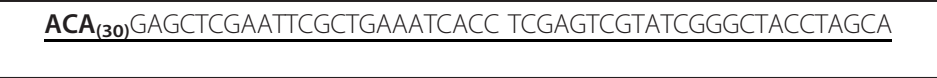 & Fragment of pBIN61 (PCR2) ${ }^{d}$ & 10.7 \\
\hline $\begin{array}{l}\text { PCR3F } \\
\text { PCR3R }\end{array}$ & $\frac{\text { TGCTAGGTAGCCCGATACGACTCGAGGGGGTGGAGCTTCCCATTGCG }}{\text { ATCAACTCGAGTCGGTCGAAAAAAG }}$ & Fragment of Yeast-pBS70T (PCR3) ${ }^{d}$ & 2 \\
\hline $\begin{array}{l}\text { PCR4F } \\
\text { ACPCR4R }\end{array}$ & $\begin{array}{l}\text { CTIITICGACCGACTCGAGTTGATGGCGGTCCTGGGGGCTA } \\
\text { TGTACACTGTATCAGTATCACCTCTCCAAATGAAATGAACTT }\end{array}$ & Fragment of Yeast-pBS70T (PCR4) $^{d}$ & 2 \\
\hline $\begin{array}{l}\text { LEV-R } \\
\text { AC-F2 }\end{array}$ & $\begin{array}{l}\text { CGGCTCGTATGTTGTGTGGA } \\
\text { ITTCTACTACGCCTGAAGTGG }\end{array}$ & $\begin{array}{l}\text { Junction between } 35 \text { S promoter and ACLSV } \\
\text { FL-CDNA }\end{array}$ & 0.5 \\
\hline
\end{tabular}

a: The regions of homology introduced in the various primers to allow homologous recombination between fragments are underlined while ACLSV sequences are indicated in bold.

b: The amplified fragments have been used for cloning the ACLSV T7-FL-cDNA in Yeast-pBS70T vector

c: The amplified fragments have been used for cloning ACLSV 70S-FL-cDNA in Yeast-pBS70T shuttle vector

$\mathrm{d}$ : The amplified fragments have been used for cloning ACLSV 35S-FL-cDNA in ternary Yeast-E. coli-A. tumefaciens shuttle vector

and difficult to reproduce. Both yield of the correct size product and limitation of unwanted, shorter products were improved by using 10-fold diluted first-strand cDNAs (Result not shown).
Full length RNA molecules of $~ 7.6 \mathrm{kbp}$ were transcribed readily in vitro using the T7 RNA polymerase and the purified RT-PCR amplicons (Figure 1b). A high yield of transcripts, up to $30 \mu \mathrm{g}$ from about $200 \mathrm{ng}$ of

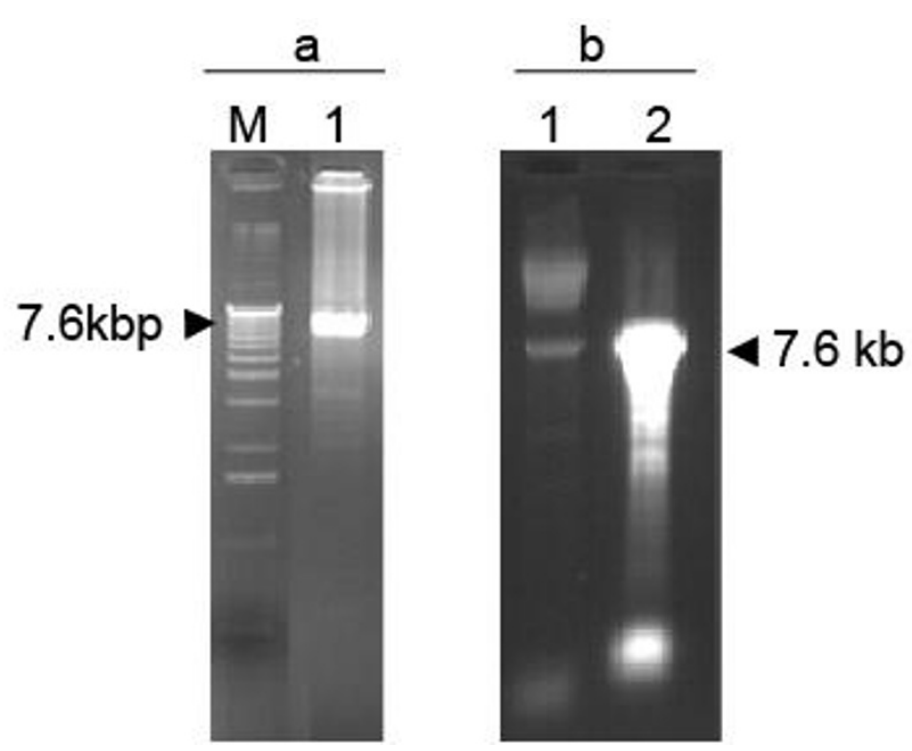

Figure 1 Agarose gel electrophoresis analysis of ACLSV full length amplification products and of in vitro transcription products derived from them. (a) Analysis on a $0.8 \%$ non-denaturing agarose gel of the T7-FL-cDNA LD-RT-PCR amplification product (lane 1) and of molecular mass markers (Invitrogen $1 \mathrm{~kb}$ ladder, lane M); (b) Analysis on a 1\% denaturing agarose gel of the T7-FL-cDNA transcription products (lane 2) compared with the input purified T7-FL-cDNA LD-RT-PCR amplification product (lane 1). 
input DNA template, was obtained, even in the presence of a cap analog to insure the synthesis of capped transcripts. As shown in Table 2, the obtained transcripts were infectious when rub-inoculated to young $C$. quinoa plants. The possibility that the observed infectivity might result from ACLSV genomic RNA carried over from the TNA extract used as template for the first-strand cDNA synthesis was ruled out by digesting the FL-cDNA PCR product with KpnI before the in vitro transcription reaction and inoculating the resulting truncated transcripts, which never gave rise to plant infection (Result not shown). The transcripts obtained from PCR products generated using the high fidelity Phusion ${ }^{\circledR}$ polymerase seem to have a higher infectivity than those prepared using the Advantage ${ }^{B}$ GC Genomic LA Polymerase Mix. Unfortunately, amplification using the Phusion ${ }^{\circledR}$ enzyme was far less reproducible than with the lower fidelity enzyme mix. In C. quinoa, the transcripts were also found to be infectious upon biolistic inoculation (Results not shown) but because of the cost of this technique and of the fact that it did not seem to bring about an improvement in inoculation efficiency over mechanical inoculation, this was not pursued further.

Surprisingly, inoculation of another herbaceous host of ACLSV, Nicotiana occidentalis 37B, never gave rise to infection despite the fact that high infection rates were observed in C. quinoa using the same batches of transcripts in parallel experiments (Table 2). The transcripts were also inoculated to ACLSV woody hosts (GF305 peach or apple), either by mechanical (stem slashing of young GF305 peach seedlings) or biolistic inoculation (germinating GF305 peach or apple seedlings), but none of the plants thus treated developed ACLSV infection (Result not shown).

\section{Table 2 Infection rates of two ACLSV hosts following mechanical inoculation of in vitro transcripts obtained from ACLSV FL-CDNA under the T7 promoter synthesized using two different PCR enzymes}

\begin{tabular}{ccc}
\hline $\begin{array}{c}\text { Enzyme used for LD- } \\
\text { PCR }\end{array}$ & \multicolumn{2}{c}{ Infected/inoculated plants $(\%$ infected) } \\
& & \\
\cline { 2 - 3 } & $\begin{array}{c}\text { Chenopodium } \\
\text { quinoa }\end{array}$ & $\begin{array}{c}\text { Nicotiana occidentalis } \\
\text { 37B }\end{array}$ \\
\hline Advantage GC $^{c}$ & $8 / 36(22 \%)$ & $0 / 22(0 \%)$ \\
Phusion $^{d}$ & $30 / 36(83 \%)$ & $0 / 22(0 \%)$ \\
water inoculation $_{\text {control }}$ & $0 / 12(0 \%)$ & $0 / 12(0 \%)$ \\
\end{tabular}

a: the results shown are the sum of two inoculation experiments performed with transcripts deriving from PCR products resulting from different amplification reactions.

b: plants were mechanically inoculated using $5 \mu \mathrm{g}$ of transcripts per plant. c: Advantage ${ }^{\circledR}$ GC Genomic LA Polymerase Mix (Clontech)

d: Phusion ${ }^{\mathbb{R}}$ High Fidelity DNA Polymerase (Finnzyme)

e: plants were rub inoculated using the DEPC-treated sterile water used to resuspend the in vitro transcripts.
One-step cloning by homologous recombination in yeast cells of ACLSV FL-cDNAs

Although uncloned infectious FL-cDNAs under the control of either the T7 or the CaMV 35S promoters might be very useful for the validation of many etiological hypotheses, cloned infectious cDNAs are also of great potential interest. However, the cloning of large PCR products often shows a very low efficiency and thus it was decided to utilize the efficient homologous recombination properties of the yeast $S$. cerevisiae to generate FL-cDNAs. Experiments were conducted in parallel using either a T7 FL-cDNA obtained as described above or a FL-cDNA without added terminal sequences amplified using the ACLSVF/FLAC3 primer pair (Table 1). Figure 2B illustrates the strategy of cloning of the T7 FL-cDNA in the shuttle vector Yeast-pBS70T.

The receiving Yeast-pBS70T vector was amplified using the divergent 30ANotvec/T7ACR or 30ACNOSF/ AC35SR primer pairs (Table 1 and Figure 2) to generate a linear $(\sim 5.2 \mathrm{kbp})$ form of the plasmid having $30 \mathrm{bp}$ regions of homology with the ACLSV T7 FL-cDNA or FL-cDNA to be cloned, respectively. Yeast cells were then transformed with equimolar amounts of the two PCR products (linear plasmid and ACLSV FL-cDNA to be cloned). Homologous recombination between the two linear molecules produces a circular plasmid which can replicate and allow the expression of the TRP1 selection marker. Yeast cells harboring recombinant plasmids were pooled, grown under selection pressure and a pool of recombinant plasmids extracted from these yeast cells used to transform $E$. coli cells by electroporation. For each cloning experiment, recombinant plasmids from 94 E. coli colonies were checked by directly amplifying the junction between the vector and the ACLSV FL-cDNA using primer pair LEV-R/AC-F2 (Table 1). For the cloning of the FL-cDNA under the T7 promoter, 60 colonies (64\%) gave a positive amplification signal while the corresponding value was 49 colonies $(52 \%)$ for the cloning under the $70 \mathrm{~S}$ promoter.

The plasmids harbored by the colonies giving a positive amplification were then extracted and submitted to restriction enzyme mapping (Figure 2C). In total, 40 and 30 recombinant plasmids had the expected BglII restriction pattern and were considered as candidates for the cloned T7-cDNA and 70S-cDNA, respectively. Pools of 10 such plasmids were then prepared and their infectivity assayed by mechanical inoculation of in vitro transcripts prepared from the NotI-linearized plasmids pools (T7-cDNA, Figure 2D \&2E) or by biolistic inoculation of the plasmid pools themselves (70S-cDNA). For pools showing infectivity, the infectivity of the 10 pooled plasmids was then individually evaluated.

The results obtained are presented in Table 3 . In the case of the ACLSV FL-cDNA cloned under the control 


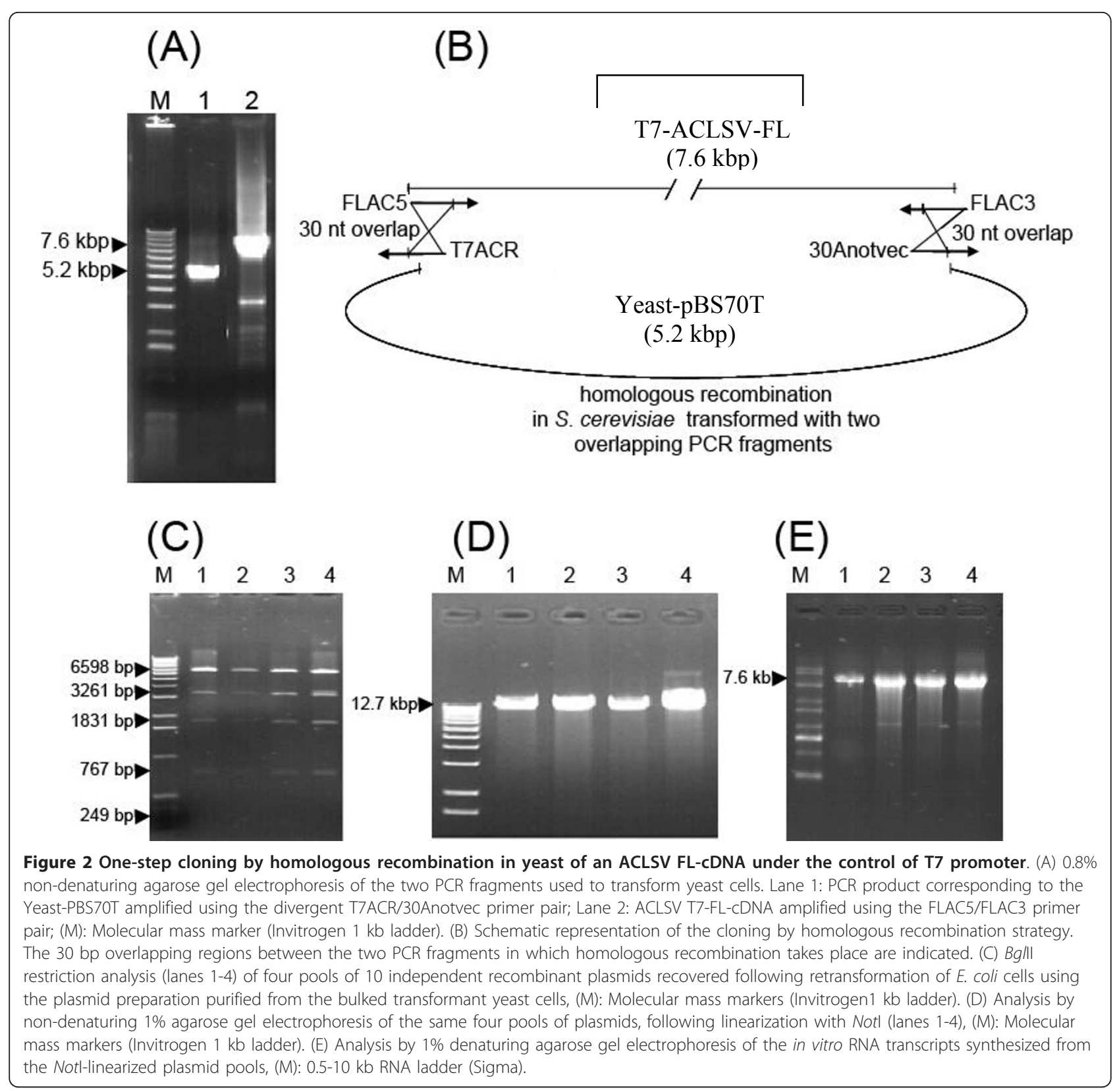

Table 3 Infectivity on Chenopodium quinoa plants and number of infectious plasmids in plasmid pools obtained upon cloning by homologous recombination in yeast cells of ACLSV FL-cDNA under the control of the T7 promoter (T7cDNA) or of the duplicated 355 promoter (70S-cDNA)

\begin{tabular}{ccc}
\hline Plasmid pools & Infected/inoculated C. quinoa plants $^{\text {a }}$ & Infectious plasmids per pool $^{-}$ \\
\hline T7-cDNA Pool 1 & $0 / 10$ & 0 \\
T7-cDNA Pool 2 & $0 / 26$ & 0 \\
T7-cDNA Pool 3 & $10 / 16$ & 1 \\
T7-cDNA Pool 4 & $0 / 26$ & 0 \\
\hline 70S-cDNA Pool 1 & $5 / 6$ & 1 \\
70S-cDNA Pool 2 & $4 / 6$ & 1 \\
70S-cDNA Pool 3 & $0 / 12$ & 0 \\
\hline
\end{tabular}

a: $3 \mu \mathrm{g}$ of capped transcripts per C. quinoa plant were used for inoculation of transcripts from T7-cDNA plasmid pools while about $160 \mathrm{ng}$ of plasmids were used per plant for biolistic inoculation of 70S-CDNA pools (2 shots per plant). 
of the T7 promoter (T7-cDNA), a single pool (Pool 3) showed infectivity and deconvolution of that pool allowed the identification of a single plasmid from which infectious in vitro transcripts could be produced. As expected from the experiments with the uncloned T7-cDNA products, no infectivity was observed upon inoculation of the transcripts derived from this recombinant plasmid to N. occidentalis 37B (Result not shown).

In the case of the ACLSV FL-cDNA cloned under the control of the 70S promoter (70S-cDNA), two of the 3 tested pools led to infection of the inoculated plants (Pools 1 and 2) and, upon deconvolution, each pool was shown to contain a single infectious plasmid (Table 3). For the two ACLSV FL-cDNA cloning attempts the rate of recovery of infectious clones is therefore of about $1-2 \%$.

\section{One-step cloning of ACLSV FL-CDNA and construction of a ternary Yeast-E. coli-A. tumefaciens shuttle vector to generate an agroinoculable ACLSV infectious cDNA clone} The use of infectious FL-cDNA constructs that can be inoculated by agroinfection or by agroinfiltration often results in a higher rate of infected plants or may allow the successful inoculation of hosts that could not be infected upon mechanical or biolistic inoculation [see for example [16]]. We therefore decided to try to obtain an infectious agroinoculable ACLSV FL-cDNA construct. This was achieved in a single step of simultaneously assembling a ternary Yeast-E. coli-A. tumefaciens shuttle vector and cloning the ACLSV FLcDNA in this vector. For this purpose, four overlapping PCR fragments were assembled by homologous recombination in yeast (Figure 3). Following transfer to E. coli of the recombinant plasmids isolated from yeast cells growing under selection, restriction mapping with EcoRI showed that 36 of the 40 tested E. coli colonies contained a plasmid with the expected restriction pattern (Figure 3E and 3F). These 36 plasmids were pooled into three pools of 12 plasmids and the infectivity of these three pools was evaluated. Given that the ACLSV FLcDNA is cloned in the ternary vector under the control of the $35 \mathrm{~S}$ promoter, this construct is expected to be infectious either as purified plasmid inoculated by biolistic bombardment or by agroinoculation of A. tumefaciens cells harboring it. Both inoculation strategies were therefore evaluated for each pool of recombinant plasmids: biolistic inoculation of C. quinoa plants or agroinfiltration of C. quinoa or N. occidentalis 37B plants. The results are presented in Table 4.

Of the three pools tested, one gave successful inoculation of C. quinoa plants by either of the inoculation techniques used or of $N$. occidentalis 37B plants by agroinfiltration. Deconvolution of this pool allowed the identification of a single infectious recombinant ternary vector (pYEA-ACLSV). Biolistic bombardment of C. quinoa with purified YEA-ACLSV resulted in a $60 \%$ infection rate, which is to be compared with the $90 \%$ infection rate observed using plasmid pCLSF under similar inoculation conditions (2 shots per plant, $50 \mathrm{ng}$ purified plasmid per plant). Inoculation by agroinfiltration with $A$. tumefaciens cells carrying pYEA-ACLSV resulted in infection rates of $91 \%$ and $67 \%$ for C. quinoa (a total of 33 inoculated plants in 3 experiments) or $N$. occidentalis 37B (a total of 18 inoculated plants in 3 experiments), respectively.

Inoculation by agroinfiltration of pYEA-ACLSV to young GF305 peach seedlings demonstrated that this construct was also able to generate infection in this woody host since 2 out of the 7 inoculated plants were later shown to be infected (result not shown).

As a control, a FL-cDNA was amplified directly from pCLSF and similarly cloned in a ternary Yeast-E. coli-A. tumefaciens shuttle vector. Out of 64 analyzed recombinant plasmids, 50 had the expected EcoRI restriction pattern and were divided into 5 pools of 10 plasmids. All pools proved infectious when inoculated either by biolistic or by agroinfiltration, in either C. quinoa or $N$. occidentalis. Individual testing of 3 randomly selected plasmids from each of those five pools revealed all of them to be infectious (Results not shown).

\section{Discussion}

Long Distance (LD) RT-PCR amplification had been used successfully to generate infectious uncloned PCR products $[24,26]$ but starting with purified viral RNA preparations obtained from purified viral particles. The need for such purified viral RNA preparations constitutes a severe limitation, in particular for viruses infecting woody hosts and for which alternative herbaceous hosts and/or purification techniques may not be available. Although the results presented here were obtained with total extracts from $C$. quinoa, recently the same technique was used successfully to amplify the complete genome of several isolates of Apricot latent virus (ApLV, 9.2-9.3 kb) from total RNA extracts obtained from infected GF305 peach seedlings, which indicates that the protocol developed is not limited to herbaceous hosts extracts or to the $7.5 \mathrm{~kb}$ length of the ACLSV genome (F. Youssef et al., unpublished). On the other hand, it was not possible to obtain similar results when using viral double-stranded RNA (dsRNAs) preparations or immunocaptured virions. Given the infectivity of the pYEA-ACLSV agroinoculable construct to GF305 peach seedlings, all the steps seem today at hand for going from TNA extracts obtained from woody hosts to successful inoculation of such woody hosts using uncloned or cloned constructs. The efficiency of such a process remains, however, to be directly evaluated. Similarly, 


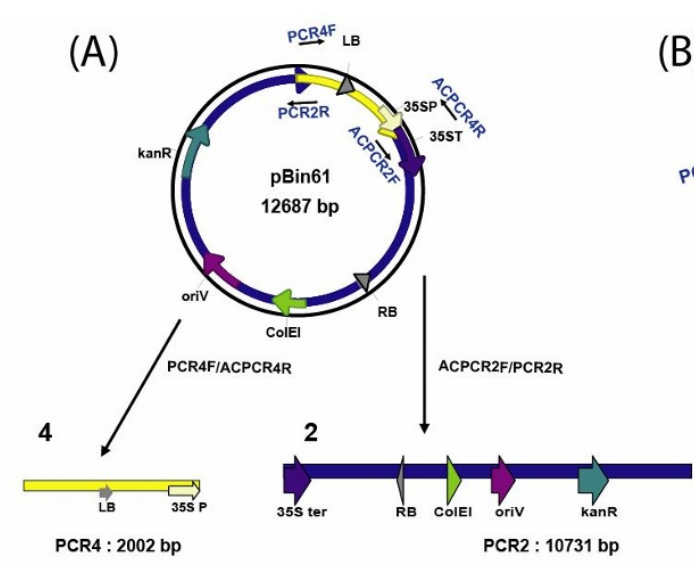

(D)

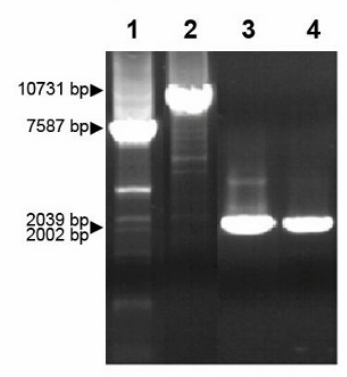

(E)

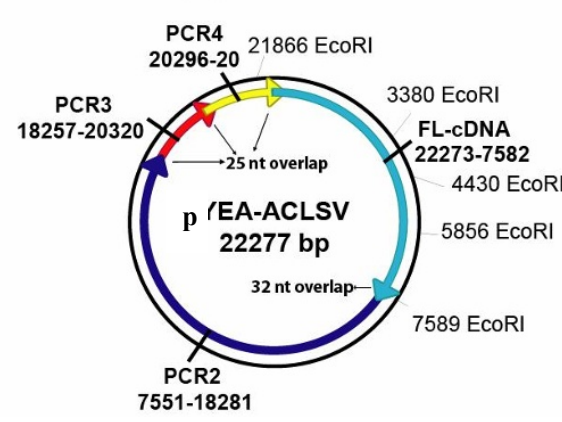

(C)

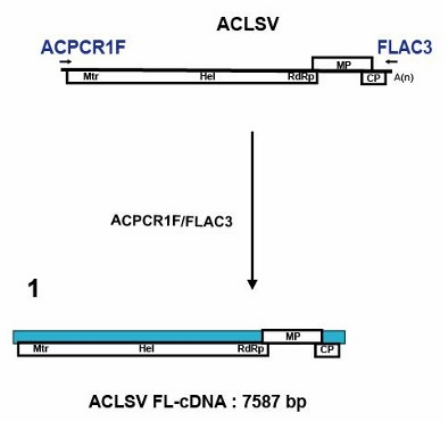

(F)

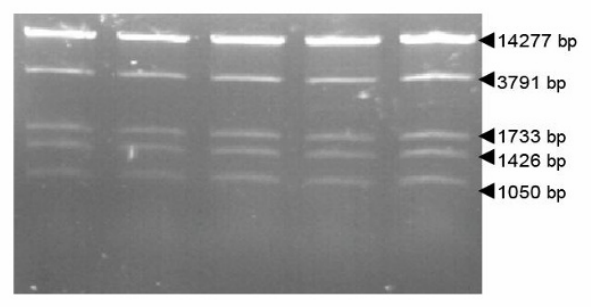

Figure 3 One-step assembly by homologous recombination in yeast of a ternary Yeast-Escherichia coli-Agrobacterium tumefaciens shuttle vector and simultaneous cloning of an ACLSV FL-CDNA to generate an infectious agroinoculable full-length viral cDNA clone. ( $A, B, C)$ Schematic representation of the strategy used to generate the four PCR fragments from which the construct is assembled by homologous recombination. The primers used are indicated by blue arrows near the respective PCR templates and are listed in Table 1. Regulatory elements are indicated by arrows of various colors. LB: T-DNA left border; 35S P: CaMV 355 promoter; 355 ter: CaMV 355 terminator; RB: T-DNA right border; ColE1: E. coli ColE1 origin of replication; oriV: A. tumefaciens oriV origin of replication; KanR: kanamycin resistance gene; $2 \mu$ Ori: yeast $2 \mu$ origin of replication; TRP1: yeast TRP1 selection gene. (A) Map of pBin61 from which are amplified the $\sim 10.7 \mathrm{kbp}$ fragment (PCR2, dark blue, carrying the $35 \mathrm{~S}$ ter, the RB, the ColE1 and OriV replication signals and the KanR selection marker) and the $\sim 2 \mathrm{kbp}$ fragment (PCR4, yellow, carrying the LB and the 355 promoter) using respectively primer pairs ACPCR2F/PCR2R and PCR4F/ACPCR4R. (B) Map of YeastpBS70T used to amplify the $\sim 2$ kbp fragment (PCR3, red, carrying the yeast $2 \mu$ Ori-TRP1) using the PCR3F/PCR3R primer pair. (C) Genomic organization of ACLSV and position of the ACPCR1F/FLAC3 primer pair used to amplify the FL-viral CDNA (PCR1, light blue). (D) Non-denaturing $0.8 \%$ agarose gel electrophoresis of the four purified overlapping PCR products. (E) Schematic representation of the recombinant YEA-ACLSV ternary plasmid carrying the ACLSV FL-cDNA obtained by assembly by homologous recombination of the four fragments. The position of EcoRI sites used for restriction mapping of the plasmid is shown. (F) Non-denaturing $0.8 \%$ agarose gel electrophoresis of 5 independently obtained recombinant plasmids showing the expected EcoRI digestion pattern.

Table 4 Infectivity of pools of agroinoculable ternary Yeast-Escherichia coli-Agrobacterium tumefaciens shuttle vectors containing the ACLSV FL-CDNA under the control of the 35S promoter assembled by one-step homologous recombination-based cloning in yeast

\begin{tabular}{ccccc}
\hline Plasmid pools $^{\mathbf{a}}$ & Infected/biolistically inoculated $^{\mathbf{b}}$ & \multicolumn{2}{c}{ Infected/Agroinoculated $^{\mathbf{c}}$} & Infectious plasmids per pool $^{\text {C. quinoa }}$ \\
\cline { 3 - 4 } & $0 / 6$ & C. quinoa & N. occidentalis 37B & 0 \\
\hline 1 & $0 / 6$ & $0 / 6$ & $0 / 5$ & 0 \\
2 & $3 / 5$ & $0 / 6$ & $0 / 5$ & 0 \\
3 & $4 / 6$ & $2 / 4$ & 1 \\
\hline
\end{tabular}

a: each pool was composed of 12 recombinant plasmids showing the expected restriction mapping results

b: biolistic inoculation was performed using two shots par plant and $100 \mathrm{ng}$ of the pool of purified plasmids per shot (about 8 ng of individual plasmid per shot). c: Agroinoculation was performed by infiltrating two leaves of each plant with the suspension of agrobacterium cells. 
whether the presence in the original host of several viral strains in mixed infection (as often observed in woody hosts) will reduce the efficiency of production of infectious constructs remains to be evaluated.

All three evaluated enzymes (Advantage ${ }^{\circledR}$ GC Genomic LA Polymerase Mix, Expand High Fidelity PCR System and Phusion ${ }^{\circledR}$ High Fidelity DNA Polymerase) allowed, although with variable efficiency and reproducibility, the amplification of the T7-FL-cDNA. The results obtained in the present work indicate that the inoculation efficiency may vary considerably depending on the inoculated host species. While such an observation is not overly remarkable when comparing the inoculation of herbaceous hosts with that of the notoriously more difficult woody hosts, the large difference observed when comparing mechanical (Table 2) or biolistic (results not shown) inoculation of in vitro transcripts on C. quinoa and on $N$. occidentalis $37 \mathrm{~B}$ is more surprising. Several hypotheses can be proposed to explain this observation, including an intrinsic difference in the susceptibility of these two host plants, possibly linked with a more rapid degradation of inoculated transcripts in $N$. occidentalis or, on the contrary, the need for host-specific adaptative mutations in ACLSV in order to infect this host. The fact that, contrary to the situation in $C$. quinoa, a significant proportion of $N$. occidentalis plants sometimes escape infection upon mechanical inoculation with crude plant homogenates, even when the viral isolate used had been passaged in this host argues against the second hypothesis. However, further experiments are required to clarify this point that could have important practical implications in view of the fact that $N$. occidentalis is the only herbaceous host known for many fruit tree-infecting Betaflexiviridae. In this respect, conflicting results were reported previously, since Saldarelli et al. [26] were able to infect this host with transcripts of the Grapevine virus $A$ and Grapevine virus $B$ vitiviruses while Vives et al. [16] could only obtain Citrus leaf blotch virus infection when using agroinoculation of a full-length construct.

Although PCR-amplified viral FL-cDNA molecules have been cloned with success in $E$. coli vectors [for example [12,13,16,19,21-23]], such cloning frequently is difficult, in particular for large FL-cDNAs. We therefore evaluated the potential usefulness of the yeast homologous recombination system for the one-step cloning of the ACLSV FL-cDNAs. As demonstrated by the successful simultaneous assembly of the ternary shuttle vector and cloning of the ACLSV FL-cDNA, this system is indeed versatile and efficient. Given that it has been used for the simultaneous assembly of numerous large DNA fragments [28], it should not prove particularly sensitive to the size of the cloned viral genome. However, in the experiments reported here, infectious plasmids only represented a fraction of all plasmids that showed the expected pattern upon restriction mapping (from $2.5 \%$ to $6.5 \%$ depending on experiment). A similarly low rate of recovery of infectious cDNA clones was reported for another Betaflexiviridae, CLBV [16]. Spetz et al. [19] reported a very low recovery of infectious constructs and the only recovered plasmid showed different biological properties than the input virus. In the experiments reported here, the rate of recovery of infectious constructs was dramatically improved when a FLcDNA amplified from an infectious cDNA clone was used instead of one amplified from total RNAs from infected plants. The low rate of recovery of infectious constructs might be due to either a low rate of infectious molecules in the starting viral RNA population and/or the introduction of detrimental mutations by the reverse transcription step but seem to exclude an impact of the PCR amplification step. In any case, the pooling strategy reported here allowed the efficient and rapid identification of the few infectious clones. It could probably be further improved by using a two or three dimensional pooling approach, so that individual infectious molecules could be identified in a single step. The potential to assemble multiple DNA fragments [28] could also be exploited to join in a single step partial cDNA fragments spanning the very long genomes [29] of viruses such as members of the Closteroviridae family.

\section{Conclusions}

We report here for the first time a set of techniques and amplification conditions that allow the use of the crude total RNA extracts from ACLSV infected C. quinoa plants as templates for the Long Distance (LD) RT-PCR amplification of infectious full-length viral cDNAs. As far as we can ascertain, this represents the largest RNA plant virus genome amplified by PCR from TNA extracts. We also demonstrate that homologous recombination in yeast allows for the fast and efficient cloning of infectious FL-cDNAs and/or one-step tailoring of complex constructs.

Overall the strategies reported here allow for the rapid generation of uncloned or cloned infectious FL-cDNA from total RNA preparations from infected hosts and should prove useful in a range of studies, and, in particular, for the validation of etiological hypotheses involving difficult to manipulate plant viral agents.

\section{Materials and methods}

\section{Virus source and RNA extraction}

The P-205 Japanese strain of ACLSV, [34], was provided by Dr. N. Yoshikawa (Iwate University, Japan) as an infectious cDNA clone under the control of the CaMV $35 \mathrm{~S}$ promoter, pCLSF [36]. The viral isolate obtained 
upon biolistic inoculation of pCLSF to C. quinoa was propagated in this host by mechanical inoculation and used as source of virus or of viral nucleic acids. Total nucleic acids were extracted with the SV Total RNA Isolation System (Promega, Lyon, France) from $30 \mathrm{mg}$ of leaf tissue from symptomatic C. quinoa plants, following the manufacturer's instructions. The yield was approximately $15 \mu \mathrm{g}$ of RNAs in $60 \mu \mathrm{l}$ of sterile water.

\section{Full-length ACLSV CDNA amplification using Long Distance (LD) RT-PCR}

Synthesis of the first-strand cDNA was primed with oligonucleotide FLAC3: 5' T(30)GTAGTAAAATATTTAAAAGTCTACAG 3', which is complementary to the 3'-terminal nucleotides (positions 7552-7527) of the genomic RNA of ACLSV-P205 (GenBank D14996). The synthesis was performed using about $1 \mu \mathrm{g}$ of TNA and the PrimeScript ${ }^{\mathrm{TM}}$ Reverse Transcriptase (Clontech/TaKaRa Bio Europe, Saint-Germain en Laye, France) or the Expand Reverse Transcriptase (Roche Diagnostics, Meylan, France), following the manufacturer instructions. In order to obtain a FL-cDNA under the control of the T7 promoter, primer FLAC5 (5' TAATACGACTCACTATAGTGATACTGATACAGTGTACACTCACG 3') was used in combination with FLAC3 in a LD-PCR experiment. FLAC5 contains the T7 promoter (in bold and italic) and the first 265 ' nucleotides of the genome of ACLSV-P205. Three commercial DNA polymerases or DNA polymerases mixes were compared for their efficiency in this study: the Advantage ${ }^{\circledR}$ GC Genomic LA Polymerase Mix (Clontech), the Expand High Fidelity PCR System (Roche) and the Phusion ${ }^{\mathbb{B}}$ High Fidelity DNA Polymerase (Finnzyme/Fischer Scientific, Illkirch, France). All enzymes were used according to their supplier recommendations, using as template $3 \mu \mathrm{l}$ from the first strand CDNA product either undiluted or diluted 10-fold. All PCRs were performed in a $25 \mu \mathrm{l}$ final reaction volume. The PCR cycling parameters recommended by the suppliers were used, with the exception of the annealing temperature which was fixed at $60^{\circ} \mathrm{C}$ for all experiments. Amplicons were purified using the MSB ${ }^{\circledR}$ Spin PCRapace kit (Invitek, les Ullis, France) and eluted in Diethylpyrocarbonate (DEPC) treated, distilled water. They were then quantified by electrophoresis on non-denaturing agarose gels and image analysis using the Image J 1.42q software (W. Rasband, NIH, USA). As a control in some experiments, LD-PCR amplification was performed directly on the pCLSF infectious plasmid instead of on cDNAs obtained from TNA extracts.

\section{T7 RNA polymerase in vitro transcription of ACLSV FL- CDNAs}

Two hundred nanograms of purified ACLSV FL-cDNA amplicons were used in in vitro transcription reactions performed using the phage T7 RNA polymerase and the
mMESSAGE mMACHINE kit (Ambion, Courtaboeuf, France) in the presence of the cap analogue $\mathrm{m}^{7} \mathrm{G}\left(5^{\prime}\right) \mathrm{ppp}$ $\left.{ }^{\prime} 5^{\prime}\right) \mathrm{G}$ (Ambion). At the end of the synthesis, which was performed as recommended by the kit supplier, transcripts were treated with $1 \mu$ of TURBO DNase (Ambion) and then used either directly or after purification on Macro SpinColumn ${ }^{\mathrm{TM}} \mathrm{G}-50$ (Harvard Apparatus, Les Ullis, France) following the manufacturer's instructions. Transcripts were quantified as described above for the PCR products and, if necessary, were stored at $-80^{\circ} \mathrm{C}$ until use in plant inoculation assays.

\section{Inoculation of herbaceous or woody ACLSV host plants}

The ACLSV FL-RNA transcripts were inoculated on young (four leaf stage) plants of C. quinoa or N. occidentalis $\mathrm{cv}$. 37B by gently rubbing $5 \mu \mathrm{l}$ of in vitro transcripts (adjusted to the desired concentration with DEPC-treated distilled water) on two celite-dusted leaves of each plant (Celite 545, 0,01-0,04 mm, Merck/ VWR, Fontenay-sous-Bois, France). Following inoculation, leaves were rinsed briefly with distilled water. As control, plants were inoculated using DEPC-treated distilled water without RNA transcripts. All plants were grown (16 hours day/8 hours night) and observed weekly for symptoms development.

Alternatively, the ACLSV FL-RNA transcripts were biolistically inoculated on leaves of young C. quinoa plants using the Helios Gene Gun (Bio-Rad/Marnes-La-Coquette, France). For inoculation, $5 \mu \mathrm{g}$ of transcripts were used to prepare 10 cartridges as recommended by Bio-Rad, using 1 $\mu \mathrm{m}$ gold particles. Each plant was bombarded on two leaves, using a 200 psi pressure. For the inoculation of woody host plants, young germinating peach (Prunus persicae, cv. GF305) or apple (Malus domestica) seedlings were inoculated when the growing radicle had reached a length of about $0.5-1 \mathrm{~cm}$. Briefly, the envelopes of germinating seeds were gently removed and the cotyledons were then inoculated by biolistic bombardment (1 shot on each of the cotyledons for the GF305 and 3 shots for groups of 10 germinating seeds for $M$. domestica. After inoculation, seeds were rinsed with distilled water and then placed on wet tissue paper in Petri dishes at $4^{\circ} \mathrm{C}$ in the dark for 24 hours. The next day, they were treated by a broad spectrum fungicide by soaking for $30 \mathrm{~min}$ in a $0.5 \%$ solution of Propamocarb- $\mathrm{HCl}$ followed by rinsing with water. The germinating embryos were finally transplanted to sterile moist sand and left to develop in the greenhouse up to the 4-leaf stage before being transplanted into pots containing potting soil. As control, plants were biolistically inoculated using the infectious pCLSF plasmid.

\section{ACLSV detection in inoculated plants}

ACLSV was detected as described [37], using doubleantibody sandwich enzyme-linked immunosorbent assay 
(DAS-ELISA) and immunoglobulins from the P2 polyclonal antiserum raised against the P863 ACLSV isolate (INRA, Bordeaux, France). Alternatively, ACLSV infection was detected using the A52-A53 ACLSV-specific RT-PCR assay described [38]. Identity of the amplified virus was confirmed by direct sequencing of the amplification products (Beckman Coulter Genomics, Meylan, France).

\section{One step cloning of ACLSV FL-CDNAs by homologous recombination in Saccharomyces cerevisiae}

The yeast (S. cerevisiae) strain YPH501 (MATa/MATa ura3-52 lys2-801amber ade2-101ochre trp1- $\Delta 63$ his3$\Delta 200$ leu2- $\Delta 1$ ) was used [39]. The yeast-E. coli vector used in these experiments is a pBS70T plasmid [40] in which a DNA fragment containing a yeast $2 \mu$ origin of replication and the yeast TRP1 gene as a selection marker has been inserted (Yeast-pBS70T). The pBS70T backbone provides an $E$. coli ColE1 origin of replication and an ampicillin resistance gene for selection in E. coli, in addition to signals for transcription in planta: duplicated CaMV 35 S promoter (70SP) and Nopaline synthase gene terminator (NosT) of the cloned FL-cDNA. The complete vector was amplified using the Phusion ${ }^{\circledR}$ High Fidelity DNA Polymerase (Finnzyme) and either one of the divergent primer pairs shown in Table 1. This strategy produces PCR products that represent a linear copy of the vector with terminal regions of $30 \mathrm{nt}$ overlapping with the ends of the FL-cDNA PCR product to be cloned. All PCR products were purified using the MSB ${ }^{\circledR}$ Spin PCRapace kit before use.

Yeast cultures were grown at $30^{\circ} \mathrm{C}$ in YPD medium (1\% yeast extract, $2 \%$ peptone, $2 \%$ glucose) prior to transformation and in SD (Minimal synthetic defined Base) selective medium with the mixture of the amino acid without tryptophan (-Try DO, Dropout) after transformation. Yeast was transformed using a lithium acetate method and denatured carrier DNA as described [41], following the modifications of [30]. Approximately 1-2 $\mu \mathrm{g}$ in total of the mixture of the PCR fragments in equimolar amounts were used per transformation. All yeast colonies growing on the selection plates following transformation were collected in $3 \mathrm{ml}$ of SD liquid medium and grown for $12 \mathrm{~h}$ at $30^{\circ} \mathrm{C}$. Plasmid DNA was isolated from these cultures according to [42] and used for transformation of E. coli cells (XL1) by electroporation. Further characterization of the recombinant plasmids and their large-scale purification were carried out using standard protocols [43]. All junctions in the recombinant plasmids obtained were confirmed by sequencing (Beckman Coulter Genomics).

One step construction of an agroinoculable ACLSV FLCDNA in a ternary yeast-E. coli-A. tumefaciens vector ACLSV FL-cDNA was cloned in a de novo constructed ternary yeast-E. coli-A. tumefaciens vector by homologous recombination in yeast cells. This was achieved by simultaneous transformation of yeast cells using 4 PCR products having 25-32 bp overlapping ends derived from the PCR primers (Figure 3 and Table 1). Besides the ACLSV FL-cDNA, the three fragments used were: (1) a $10.7 \mathrm{kbp}$ product covering the $35 \mathrm{~S}$ terminator, the T-DNA right border (RB), the E. coli ColE1 origin of replication, the $A$. tumefaciens OriV origin of replication and finally the kanamycin resistance gene from the pBin61 binary vector [44], (2) a 2 kbp fragment containing the yeast $2 \mu$ origin of replication and the yeast TRP1 gene derived from the Yeast-pBS70T vector described above and (3) a $\sim 2 \mathrm{kbp}$ fragment containing the T-DNA left border (LB) and the CaMV 35S promoter of pBin61. The long fragment was amplified using the Advantage ${ }^{\circledR}$ GC Genomic LA Polymerase Mix kit while the two shorter ones were amplified with the Phusion ${ }^{\circledR}$ High Fidelity DNA Polymerase. After purification of all fragments using the MSB ${ }^{\circledR}$ Spin PCRapace kit, yeast cells were transformed with a total of about 3 $\mu \mathrm{g}$ of the four fragments in equimolecular amounts. The various steps following transformation were carried out as described above and the recombinant plasmids harbored by $E$. coli colonies finally verified by restriction analysis. Plasmids showing the expected EcoRI restriction pattern were divided into pools and used to transform by electroporation (with $\sim 100 \mathrm{ng}$ of purified plasmid pools) A. tumefaciens $\mathrm{C} 58 \mathrm{C} 1$ cells carrying the pG90 helper plasmid (provided by S. Vernhettes, INRAVersailles). Agrobacterium transformants were selected on LB medium plates supplemented with $50 \mathrm{mg} / \mathrm{l} \mathrm{rifam-}$ picin, $50 \mathrm{mg} / \mathrm{l} \mathrm{kanamycin} \mathrm{and} 20 \mathrm{mg} / \mathrm{l}$ gentamycin. All transformed bacteria growing on the Petri dishes were collected and grown as pools in LB liquid medium with the same antibiotics and this culture was then used as the starter culture to prepare Agrobacterium cells for agroinfiltration.

\section{Inoculation of plants using agroinfiltration}

For agroinfiltration of plants, $A$. tumefaciens cells carrying the relevant plasmid(s) were first grown overnight at $28^{\circ} \mathrm{C}$ in $5 \mathrm{ml}$ of $\mathrm{LB}$ medium plus selection antibiotics (see above). These pre-cultures were then used to inoculate $25 \mathrm{ml}$ cultures of induction medium [LB medium supplemented with selection antibiotics, $10 \mathrm{mM}$ of $2 \mathrm{~N}$ morpholino-ethane sulfonic acid (MES) and $20 \mu \mathrm{M}$ of acetosyringone]. Following incubation overnight at $28^{\circ} \mathrm{C}$ under agitation, bacteria were collected by centrifugation at $6000 \mathrm{~g}$ for $15 \mathrm{~min}$ at room temperature, re-suspended in infiltration medium $\left(10 \mathrm{mM} \mathrm{MgCl}_{2}, 10 \mathrm{mM} \mathrm{MES,} \mathrm{pH}\right.$ 5.6, and $150 \mu \mathrm{M}$ acetosyringone) and the bacterial suspension adjusted to an optical density of 0.6 at $600 \mathrm{~nm}$. The suspension was then incubated for $3 \mathrm{~h}$ at room temperature before being infiltrated in the intercellular 
spaces of young C. quinoa or $N$. occidentalis leaves, using a syringe directly placed on the lower leaf surface. Alternatively, young GF305 peach seedlings were inoculated by injections of the Agrobacterium cells suspension in their stems using a syringe and a small gauge needle. Following their inoculation, plants were monitored weekly for symptoms appearance and ACLSV infection was confirmed as described above.

\section{List of abbreviations}

70SP: duplicated CaMV 355 promoter; ACLSV: Apple chlorotic leaf spot virus; ApLV: Apricot latent virus; CLBV: Citrus leaf blotch virus; DAS-ELISA: doubleantibody sandwich enzyme-linked immunosorbent assay; DEPC diethylpyrocarbonate; dsRNA: double stranded RNA; FL-CDNA: full-length infectious CDNA clone; LB: T-DNA left border; LD-PCR: long distance PCR; MES: $2 \mathrm{~N}$-morpholino-ethane sulfonic acid; NGS: next generation sequencing; NosT: Nopaline synthase gene terminator; RB: T-DNA right border; SD: minimal synthetic defined base; TNA: total nucleic acids; YAC: yeast artificial chromosome

\section{Acknowledgements}

FY was supported by a fellowship from the Syrian Ministry of Higher Education. The Apple chlorotic leaf spot virus infectious CDNA clone pCLSF was a generous gift of Dr. N. Yoshikawa (Iwate University, Japan), who also shared with us prior to publication his protocol for the biolistic inoculation of apple seedlings. The Agrobacterium C58C1 strain carrying the pG90 helper plasmid was provided by Dr. S. Vernhettes (INRA Versailles, France) and the YPH501 yeast strain by Dr Benoit Moury (INRA Avignon, France). We also wish to thank M. Roncoroni, T. Mauduit, and A. Bailly for taking excellent care of all the plants used in this work, Dr. Emmanuel Jacquot (UMR Bio3P, Rennes, France) for valuable discussions and suggestions and Anas AbdulRazzak (UMR GDPP, Bordeaux, France) for sharing with us his skills on cloning by homologous recombination in yeast.

\section{Author details}

'Equipe de Virologie, INRA, UMR 1332 Biologie du Fruit et Pathologie, BP81, 33883 Villenave d'Ornon cedex, France. ${ }^{2}$ Equipe de Virologie, Université de Bordeaux, UMR 1332 Biologie du Fruit et Pathologie, BP81, 33883 Villenave d'Ornon cedex, France. ${ }^{3}$ Laboratoire de Virologie, Ctifl, Centre de Lanxade, 24130 La Force, France.

\section{Authors' contributions}

All authors contributed to the results presented. FY, AM, PG and TC contributed to and edited the manuscript. All authors read and approved the final manuscript.

\section{Competing interests}

The authors declare that they have no competing interests.

Received: 8 July 2011 Accepted: 31 October 2011

Published: 31 October 2011

\section{References}

1. Fauquet CM, Mayo MA, Maniloff J, Desselberger U, Ball LA: Virus Taxonomy: Eighth Report of the International Committee of Taxonomy of Viruses London: Elsevier; 2005.

2. Al Rwahnih M, Daubert S, Golino D, Rowhani A: Deep sequencing analysis of RNAs from a grapevine showing Syrah decline symptoms reveals a multiple virus infection that includes a novel virus. Virology 2009, 387:395-401

3. Kreuze JF, Perez A, Untiveros M, Quispe D, Fuentes S, Barker I, Simon R: Complete viral genome sequence and discovery of novel viruses by deep sequencing of small RNAs: A generic method for diagnosis, discovery and sequencing of viruses. Virology 2009, 388:1-7.

4. Matthews REF: Diagnosis of Plant Virus Disease CRC Press; 1993.
5. Choi YG, Croft BJ, Randles JW: Identification of sugarcane striate mosaicassociated virus by partial characterization of its double-stranded RNA. Phytopathology 1999, 89:877-883.

6. Jelkmann W, Fechtner B, Agranovsky AA: Complete genome structure and phylogenetic analysis of little cherry virus, a mealybug-transmissible closterovirus. J Gen Virol 1997, 78:2067-2071.

7. Meng B, Meng B, Pang SZ, Forsline PL, McFerson JR, Gonsalves D: Nucleotide sequence and genome structure of Grapevine rupestris stem pitting associated virus-1 reveal similarities to apple stem pitting virus. J Gen Virol 1998, 79:2059-2069.

8. Hull R: Matthews' Plant Virology New York: Academic Press; 2002.

9. Jones A, McGavin W: Improved PCR detection of Blackcurrant reversion virus in Ribes and further evidence that it is the causal agent of reversion disease. Plant Dis 2002, 86:1333-1338.

10. Meng B, Zhu HY, Gonsalves D: Rupestris stem pitting associated virus-1 consists of a family of sequence variants. Arch Virol 1999, 144:2071-2085.

11. Boyer JC, Haenni AL: Infectious transcripts and CDNA clones of RNA viruses. Virology 1994, 198:415-426.

12. Crutzen F, Mehrvar M, Gilmer D, Bragard C: A full-length infectious clone of Beet soil-borne virus indicates the dispensability of the RNA-2 for virus survival in planta and symptom expression on Chenopodium quinoa leaves. J Gen Virol 2009, 90:3051-3056

13. Dizadji A, Koohi-Habibi M, Izadpanah K, Dietrich C, Mossahebi GH, Winter S: Characterization of Lettuce virus $X$, a new potexvirus infecting lettuce in Iran. Arch Virol 2008, 153:1867-1875.

14. Lamprecht $\mathrm{S}$, Jelkmann W: Infectious cDNA clone used to identify Strawberry mild yellow edge-associated potexvirus as causal agent of the disease. J Gen Virol 1997, 78:2347-2353.

15. Satyanarayana T, Bar-Joseph M, Mawassi M, Albiach-Marti MR, Ayllon MA, Gowda S, Hilf ME, Moreno P, Garnsey SM, Dawson WO: Amplification of Citrus tristeza virus from a cDNA clone and infection of citrus trees. Virology 2001, 280:87-96

16. Vives MC, Martín S, Ambrós S, Renovell A, Navarro L, Pina JA, Moreno P, Guerri J: Development of a full-genome cDNA clone of Citrus leaf blotch virus and infection of citrus plants. Mol Plant Pathol 2008, 9:787-797.

17. Guenoune-Gelbart D, Sufrin-Ringwald T, Capobianco H, Gaba V, Polston JE, Lapidot M: Inoculation of plants with begomoviruses by particle bombardment without cloning: Using rolling circle amplification of total DNA from infected plants and whiteflies. J Virol Methods 2010, 168:87-93.

18. Wege C, Gotthardt RD, Frischmuth T, Jeske H: Fulfilling Koch's postulates for Abutilon mosaic virus. Arch Virol 2000, 145:2217-2225.

19. Spetz C, Moe R, Blystad DR: Symptomless infectious cDNA clone of a Norwegian isolate of Poinsettia mosaic virus. Arch Virol 2008, 153:1347-1351.

20. Barnes WM: PCR amplification of up to 35-kb DNA with high fidelity and high yield from lambda bacteriophage templates. Proc Natl Acad Sci USA 1994, 91:2216-2220.

21. Hasiów-Jaroszewska B, Borodynko N, Popieszny H: Infectious RNA transcript derived from cloned cDNA of a Pepino mosaic virus isolate. Arch Virol 2009, 154:853-856.

22. Song YS, Min BE, Hong JS, Rhie MJ, Kim MJ, Ryu KH: Molecular evidence supporting the confirmation of Maracuja mosaic virus as a species of the genus Tobamovirus and production of an infectious transcript. Arch Virol 2006, 151:2337-2348.

23. You Y, Shirako Y: Bymovirus reverse genetics: requirement for RNA2encoded proteins in systemic infection. Mol Plant Pathol 2010, 11:383-394.

24. Choi SH, Ryu KH: Generation of infectious transcripts from Korean strain and mild mottle strain of Potato virus X. J Microbiol 2008, 46:502-507.

25. Fakhfakh H, Vilaine F, Makni M, Robaglia C: Cell-free cloning and biolistic inoculation of an infectious CDNA of Potato virus Y. J Gen Virol 1996, 77:519-523.

26. Saldarelli P, Dell'Orco M, Minafra A: Infectious CDNA clones of two grapevine viruses. Arch Virol 2000, 145:397-405.

27. Marykwas DL, Passmore SE: Mapping by multifragment cloning in vivo. Proc Natl Acad Sci USA 1995, 92:11701-1175.

28. Gibson DG, Benders GA, Axelrod KC, Zaveri J, Algire MA, Moodie M, Montague MG, Venter JC, Smith $\mathrm{HO}$, Hutchison CA: One-step assembly in yeast of 25 overlapping DNA fragments to form a complete synthetic Mycoplasma genitalium genome. Proc Natl Acad Sci USA 2008, 105:20404-2049. 
29. Polo $S$, Ketner $G$, Levis R, Falgout B: Infectious RNA transcripts from fulllength Dengue virus type 2 CDNA clones made in yeast. J Virol 1997, 71:5366-5374

30. Fernandez-Delmond I, Pierrugues $\mathrm{O}$, de Wispelaere M, Guilbaud L, Gaubert S, Diveki Z, Godon C, Tepfer M, Jacquemond M: A novel strategy for creating recombinant infectious RNA virus genomes. J Virol Methods 2004, 121:247-257.

31. Liang D, Gray SM, Kaplan I, Palukaitis P: Site-directed mutagenesis and generation of chimeric viruses by homologous recombination in yeast to facilitate analysis of plant-virus interactions. Mol Plant Microbe Interact 2004, 17:571-576.

32. Martelli GP, Candresse T, Namba S: Trichovirus, a new genus of plant viruses. Arch Virol 1994, 134:451-455.

33. Yoshikawa N: Apple chlorotic leaf spot virus. CMI AAB Description of Plant Viruses, No. 386 (No.30 revised) 2001

34. German S, Candresse T, Lanneau M, Huet JC, Pernollet JC, Dunez J: Nucleotide sequence and genomic organization of Apple chlorotic leaf spot closterovirus. Virology 1990, 179:104-112.

35. Sato K, Yoshikawa N, Takahashi T: Complete nucleotide sequence of the genome of an Apple isolate of apple chlorotic leaf spot virus. J Gen Virol 1993, 74:1927-1931.

36. Satoh H, Yoshikawa N, Takahashi T: Construction and biolistic inoculation of an infectious cDNA clone of Apple chlorotic leaf spot Trichovirus. Ann Phytopathol Soc Jpn 1999, 65:301-304.

37. Foissac X, Svanella-Dumas L, Gentit P, Dulucq MJ, Marais A, Candresse T: Polyvalent degenerate oligonucleotides reverse transcription-polymerase chain reaction: a polyvalent detection and characterization tool for trichoviruses, capilloviruses, and foveaviruses. Phytopathology 2005, 95:617-625.

38. Candresse T, Lanneau M, Revers F, Grasseau N, Macquaire G, German S, Malinowsky T, Dunez J: An immunocapture PCR assay adapted to the detection and the analysis of the molecular variability of the Apple chlorotic leafspot virus. Acta Hortic 1995, 386:136-147.

39. Sikorski RS, Hieter P: A system of shuttle vectors and yeast host strains designed for efficient manipulation of DNA in Saccharomyces cerevisiae. Genetics 1989, 122:19-27.

40. Yang SJ, Revers F, Souche S, Lot H, Le Gall O, Candresse T, Dunez J: Construction of full-length CDNA clones of Lettuce mosaic virus (LMV) and the effects of intron-insertion on their viability in Escherichia coli and on their infectivity to plants. Arch Virol 1998, 143:2443-2451.

41. Gietz RD, Schiestl RH: Applications of high efficiency lithium acetate transformation of intact yeast cells using single-stranded nucleic acids as carrier. Yeast 1991, 7:253-263.

42. Hofmann CS, Winston F: A ten-minute DNA preparation from yeast efficiently releases autonomous plasmid for transformation of Escherichia coli. Gene 1987, 57:267-272.

43. Sambrook J, Fritsch EF, Maniatis T: Molecular Cloning - A Laboratory Manual. Cold Spring Harbor, New York: Cold Spring Harbor Press; 21989.

44. Bendahmane A, Kanyuka K, Baulcombe DC: The Rx gene from potato controls separate virus resistance and cell death responses. Plant Cell 1999, 11:781-92.

doi:10.1186/1743-422X-8-488

Cite this article as: Youssef et al: Strategies to facilitate the development of uncloned or cloned infectious full-length viral cDNAs: Apple chlorotic leaf spot virus as a case study. Virology Journal 2011 8:488.

\section{Submit your next manuscript to BioMed Central and take full advantage of:}

- Convenient online submission

- Thorough peer review

- No space constraints or color figure charges

- Immediate publication on acceptance

- Inclusion in PubMed, CAS, Scopus and Google Scholar

- Research which is freely available for redistribution

Submit your manuscript at www.biomedcentral.com/submit
C Biomed Central 